\title{
Addressing the crisis in US health care: moving beyond denial
}

\section{Don E Detmer}

A new report published by the Institute of Medicine in November 2002 creates a "game plan" for delivering a new system of health care through a set of demonstration projects in states across the US. The goal is to see these "seeds" grow over the next decade into universally accessible, safe, evidence-based, patient centred care for the US complete with a national health information infrastructure with common operating standards, secure communications, decision support, and knowledge management.

$\mathrm{T}$ he US healthcare system is in a crisis and it is finally acknowledging this reality. Like other nations around the world, US health care faces mounting problems including rising costs, challenges to access to services, and persistently wide variations in safety and quality. Following the failure of the first Clinton Administration in the early 1990s to reform the US healthcare system through a complex "top down" approach and the managed care belt tightening of the past decade, no basic reforms have occurred. Meanwhile the population has aged another decade, causing a much greater need for integrated care to manage chronic illness, in addition to large increases in personal body mass. Efficiency measures such as robust information networks have scarcely penetrated to the level of primary care. Despite these many shortcomings, the nation has been slow to acknowledge that the healthcare Emperor is naked except for some high technology epaulettes sewn onto a backless examining gown.

In the 1980s and early 1990s Secretary of Health and Human Services Thompson, then Governor of Wisconsin, concluded that the nation's social welfare system was hopeless and too expensive, and he led the national reform through a creative statewide demonstration that then spread across the nation. In mid June 2002 he concluded the same about the current non-system of health care in the USA. He asked the Institute of Medicine for suggestions for statewide initiatives that would serve as sites to move the country forward to a far better healthcare system by 2010. Among other items he pointed to rising costs of litigation and malpractice insurance rates that were in some instances causing consultants to move to other states or retire from active practice. A "fast track" committee was created which worked through the summer and released its report in mid November.

The timing is right for action. Coming on the heels of the oft quoted Institute of Medicine reports "To Err is Human" ${ }^{\prime \prime}$ and "Crossing the Quality Chasm", ${ }^{2}$ this new report "Fostering Rapid Advances in Health Care: Learning from System Demonstrations" ${ }^{\prime 3}$ acknowledges the lacklustre performance of the current system in dealing with both safety and quality. This newest report builds on the conclusions of the first two reports by urging the creation of a healthcare system that is safe, patient centred, effective, efficient, timely, and equitable. It recognises that at present the US healthcare system meets only some of these aims some of the time, and that it can do much better. While "To Err is Human" highlighted a problem and "Crossing the Quality Chasm" created a vision for the future, this newest Institute of Medicine report creates a "game plan" for seeing the new system emerge through a set of major demonstration projects in states across the nation. Genuine working partnerships will be needed between the federal and state governments and between state and local stakeholders.

\section{"health care is a local experience, even in systems that are centralised in their management"}

Perhaps for the first time in years, Americans may coalesce around both a sound vision and a practical strategy for creating a proper care system for the future. Currently, one political party controls the White House, the Senate and the House of Representatives andalthough it is easy to forget today-at the time of his election the President was totally focused on domestic affairs. On the other hand, serious healthcare reforms in the US present a very difficult political challenge and state budgets are not conducive to expensive new experiments. Yet, something must be done and many agree on this point.

The "Rapid Advances" committee urges the federal government to support bold major (statewide, large regions, multistate) projects in five critical areas essential to a new and greatly improved healthcare system. These include:

- chronic care demonstrations in 10-12 communities;

- primary care demonstrations in 40 practice settings;

- information and communications technology in 8-10 states;

- universal health insurance coverage in 3-5 states; and

- malpractice liability projects in 4-5 states.

One-time major federal funding is requested for only one of the five, assuring a "paperless" healthcare system-for example, an information and communications technology (ICT) infrastructure to assure computer based communications and interactions among all key stakeholders, especially patients. The goal is to create computer based patient, personal, and community health records to assure secure communications, decision support, and knowledge management in regions, but using standards to make the systems interoperable and scalable at the national level. Once developed, the system is expected to assume ongoing maintenance costs. Among the options is to draw upon the excellent nationally deployed ICT system developed within the Veterans Administration over the past few years. The government run Veterans Administration care system for those who have served in the military is the largest healthcare system in the US and its ICT system has won a number of major national awards for quality improvement when in competition with the best of the private sector hospitals and clinics.

One area focuses on creating initiatives for the management of chronic illness and another set of projects would create model primary care community health centres. The US has a number of such centres across the nation, but the systems rarely have the funding to assure that their successes can and are replicated elsewhere. Robust IT systems are advocated for these centres and for the chronic illness management initiatives. Another area urges statewide approaches to guarantee timely universal access to basic care services. This initiative would also cost money, but it appears that some states such as Maine 
wish to take on this challenge. A computer based system to identify eligibility rapidly is urged.

The fifth initiative in the list focuses on the malpractice liability crisis. Two models are advocated. The first model recommended for trial is a "no fault" approach like that in Sweden. The second involves "early offers" of financial payment to patients and their families at the time of a significant adverse event or injury so that the lengthy, costly and typically unsatisfactory results of the current tort jury system may be avoided and caregivers can also apologise directly for the injury or error. Today the adversarial nature of the tort system greatly impedes such interactions and, even when a patient gets a settlement, lawyers get a significant amount of any award.

The report urges creation of ongoing private-public partnerships for states and regions. The goal is to create major new components for the future healthcare system for the nation so that over 10 years a new system of care will develop. The report shows great respect for the intelligence and goodwill which exist throughout the nation, and it believes that a mix of government and private sector input is needed to create a system that can evolve over time and also achieve and sustain the needed high levels of performance. Stated differently, a "Washington inside the Beltway" top down approach would almost certainly fail and yet, at the same time, national leadership is needed for stimulus packages, for changing regulations and barriers, and for setting ICT standards to assure a robust yet flexible national information infrastructure.

The media received the report with substantial positive fanfare. Reports available at the time of submitting this editorial suggest that President Bush will mention the initiatives in his State of the Union address in January 2003.

What lessons may be useful to other nations from this most recent report? The obvious answer is that it is too early to say. However, it is already clear that health care is a local experience, even in systems that are centralised in their management. While the US now accepts that it has a genuine healthcare crisis on its hands, it also believes that only regional approaches with national support can assure that the key stakeholders come together in constructive initiatives capable of evolving over time. Healthcare systems may require national visions of what the Emperor's robes should consist, but the stitching and final alterations will ultimately require the skills of the best seamstresses and tailors dotted across the land.

Qual Saf Health Care 2003;12:1-2

\section{Authors' affiliations}

D E Detmer, Dennis Gillings Professor of Health Management and Director, Cambridge University Health, Judge Institute of Management, University of Cambridge, UK Professor Emeritus and Professor of Medical Education, University of Virgina; and Member of the IOM Committee on "Fostering rapid advances in health care: learning from system demonstrations"; d.detmer@jims.cam.ac.uk

\section{REFERENCES}

1 Institute of Medicine. To err is human: building a safer health system. Washington, DC: National Academy Press, 2000.

2 Institute of Medicine. Crossing the quality chasm: a new health system for the 21 st century. Washington, DC: National Academy Press, 2001.

3 Institute of Medicine. Fostering rapid advances in health care: learning from system demonstrations. Washington DC: National Academy Press, 2002.

\section{Retrospective case record review: a blunt instrument that needs sharpening}

\section{G Neale, M Woloshynowych}

Retrospective case record review is a cumbersome and costly method of identifying adverse events. Although it has resulted in some very significant initiatives, more efficient methods of preliminary screening and more robust methods of contemporaneous record review are needed to enable medical directors and heads of clinical units to assess quality of care.

"Hospital medicine used to be simple, ineffective and relatively safe. Now it is complex, effective and potentially dangerous". ${ }^{1}$ The medical profession has been slow to address the dangers. Modern medical practice took off after the Second World War and within a decade the increased risks of iatrogenic disease were recognised. It was reported that admission to hospital carried a $20 \%$ chance of a "noxious" episode (excluding those caused by inadvertent errors and postoperative complications!). However, the attitude was "the dangers are generally warranted by the benefits" and "to seek absolute safety is to advocate therapeutic nihilism". ${ }^{2}$ It took claims of medical negligence by the public to rock the boat. Prompted by a tort system spiralling out of control, the insurance industry in California sponsored a study of the incidence and nature of adverse events based on retrospective case record review (RCRR). ${ }^{3}$ Despite the cumbersome and costly nature of RCRR, the method continues to be used, primarily as an epidemiological tool.

The basic review process has changed little. In phase I nurses or experienced hospital administrators are trained to identify case records that satisfy one or more of 18 well defined screening criteria that have been shown to be associated with an increased likelihood of an adverse event. In phase II trained doctors analyse positively screened records in detail to determine whether or not they contain evidence of an adverse event. ${ }^{3}$

The largest studies have been undertaken in the USA ${ }^{4}$ and Australia. ${ }^{5}$ In US studies $3-4 \%$ of case records were found to contain adverse events, of which about one quarter were found to be due to substandard (negligent) care. In Australia $16.6 \%$ of admissions were associated with an adverse event of which one half were deemed preventable. It seems unlikely that this large difference can be ascribed solely to the different aims of the two studies. About one half of the variance is probably due to methodological differences. Using American criteria the incidence of adverse events in Australian hospitals is reduced to $10.6 \%{ }^{6}$ This is similar to the incidence of adverse events in three smaller studies recently reported from London (10.8\%), Copenhagen $(9.0 \%)$, and Auckland (10.7\%). About $40 \%$ of adverse events are regarded as preventable.

So how robust is the methodology and how useful are the data? Prompted incident reporting ${ }^{7}$ and checking risk management and litigation files ${ }^{8}$ show that RCRR misses up to $20 \%$ of adverse events. Those that are revealed depend on clinical judgements. Great efforts 
have been made to strengthen the accuracy and reproducibility of these judgements but reliability remains no better than moderate. ${ }^{9}$ Furthermore, hindsight bias-the tendency to impute causation when the outcome is known-is a potential inherent weakness. In published studies causation (whether or not an adverse event is due to healthcare management rather than the disease process) and preventability are judged to the legal standard of "more likely than not" which leaves considerable room for dispute. In the Harvard study ${ }^{10}$ paired expert opinions regarding the occurrence of an adverse event showed that extreme disagreement was more common than agreement. Agreement was highest for wound infections and lowest for failure to diagnose and incorrect treatment. Experienced reviewers are more likely to agree, but even in a most careful study from Australia there was only $80 \%$ agreement on the presence of an adverse event $(\kappa=0.55)$ and $58 \%$ agreement on preventability $(\kappa=0.33)$. Testing validity-that is, the extent to which the process approximates to the true value-without a "gold standard" is even more difficult. It has been concluded that the recognition of adverse events by RCRR has only moderate face, content and construct validity. ${ }^{1 .}$

Whatever the true figure for adverse events in hospital practice, the results of RCRR need careful interpretation. In all reported studies about two thirds of adverse events either caused transient injuries (full recovery within 1 month) or occurred in very sick patients. The incidence of adverse events is higher among the elderly (probably because their conditions are more complex) and increases with the length of stay in hospital. $^{45_{12}}$ Regrettably, headline figures are dramatised by journalists who see adverse events lumped together irrespective of preventability and severity of outcome. Moreover, politicians, lawyers and healthcare managers often have difficulty in interpreting the data or use them selectively to satisfy particular agendas.

Despite these caveats, RCRR has led to some very significant initiatives. It has had an enormous and positive impact on efforts to improve hospital practice and has played an important part in the development of mission statements from the Institute of Medicine in the USA and the expert group advising the Chief Medical Officer in the UK regarding the building of safer health systems. In the USA, RCRR has triggered efforts to redesign systems in order to try to reduce the incidence of adverse events. For example, it was shown that $20 \%$ of adverse events were drug related. This has led to several studies indicating that information and decision support systems as well as improved methods for ordering, transcribing, dispensing and administering medications may reduce adverse events. $^{13}$ In contrast, Australian researchers have focused on identifying the contributory causes of human error. In more than half the adverse events they found that cognitive failure was an important trigger. To improve care they called for better-or better implemented-policies and protocols, better quality monitoring, better education and training, and more consultation. ${ }^{14}$ The UK study ${ }^{12}$ offers yet another exploratory route. Rather than trying to identify the underlying causes of specific errors by root cause analysis, stages in the hospital process at which care became suboptimal were defined and related to modes of clinical practice. In this way it may be possible to extend the value of RCRR.

However, there remains a need to devise more timely and more efficient methods of preliminary screening and more robust methods of contemporaneous record review to enable medical directors and heads of clinical units to assess quality of care. Reducing the background of low grade adverse events in hospital practice is not only vital for the improved care of patients, but also has important implications for health economics. Reported RCRR studies are remarkably consistent in finding that each adverse event equates with the use of 6-8 hospital bed-days. Furthermore, as pressure on hospital beds is a worldwide problem, there appears to be a pressing need for further and better studies.

\section{ACKNOWLEDGEMENTS}

GN thanks the BUPA Foundation and MW thanks the Dunhill Medical Trust for support in undertaking studies of the value of retrospective case record review. We are grateful to Professor Charles Vincent for discussion and helpful comments.

Qual Saf Health Care 2003;12:2-3

\section{Authors' affiliations}

G Neale, M Woloshynowych, Clinical Risk

Unit, University College, London, UK

Correspondence to: $\operatorname{Dr} G$ Neale, Clinical Risk Unit, University College, London, UK g.neale@ucl.ac.uk

\section{REFERENCES}

1 Chantler $\mathrm{C}$. The role and education of doctors in the delivery of healthcare. Hollister Lecture delivered at the Institute of Health Services Research, Northwestern University, Illinois, USA, October 1998. Lancet 1999:353:1178-81.

2 Schimmel EM. The hazards of hospitalization. Ann Intern Med 1964;60:100-10.

3 Mills DH. Medical insurance feasibility study. A technical study. West J Med 1978:128:360-5.

4 Brennan TA, Leape LL, Laird NM, et al. Incidence of adverse events and negligence in hospitalized patients. Results of the Harvard Medical Practice Study I. N Engl J Med 1991:324:370-6.

5 Wilson RM, Runciman WB, Gibberd RW, et al. The quality in Australian health care study. Med J Aust 1995; 163:458-71.

6 Thomas EJ, Studdart DM, Runciman WB, et al. A comparison of iatrogenic injury studies in Australia and the USA I: context, methods, casemix, population, patient and hospital characteristics. Int I Qual Health Care 2000;12:371-8.

7 O'Neil AC, Petersen LA, Cook EF, et al. Physician reporting compared with medical-record review to identify adverse medical events. Ann Intern Med 1993;1 19:370-6.

8 Brennan TA, Localio AR, Leape LL, et al. Identification of adverse events occurring during hospitalization. Ann Intern Med 1990:112:221-6.

9 Localio AR, Weaver SL, Landis JR, et al. Identifying adverse events caused by medical care: degree of physician agreement in a retrospective chart review. Ann Intern Med 1996; 125:457-64.

10 Caplan RA, Posner KL, Cheney FW. Effect of outcome on physician judgments of appropriatemness of care. JAMA 1991;265: 1957-60

11 Walshe $\mathrm{K}$. The reliability and validity of adverse-event measures of the quality of healthcare. University of Birmingham, 1998: $47-60$

12 Neale G, Wolopshynowych M, Vincent C. Exploring the causes of adverse events in NHS hospital practice. J R Soc Med 2001:94:322-30.

13 Bates DW, Leape LL, Cullen DJ, et al. Effect of computerized physician order entry and a team intervention on prevention of serious medication errors. JAMA 1998;280:1311-6.

14 Wilson RM, Harrison BT, Gibberd RW, et al. An analysis of the causes of adverse events from the Quality in Australian Health Care Study. Med J Aust 1999;170:411-5. 